\title{
Editorial: the vision for The Computer Games Journal
}

\author{
Written by the editors in chief
}

The computer games industry is, and always has been, an industry in rapid flux, with a wide range of products on offer, and which is reliant on a diverse range of technologies and an advanced skill base. Every week there is a new development, a new product, a technological challenge or an unexpected market trend. There is more to the industry than selling commercial games for customers' leisure: computer games and the industry's technologies have been used by the medical profession, by schools and by the military for many years.

At a recent conference at the Scottish Parliament earlier this year, Colin Anderson of Denki Studios Ltd claimed, "the games industry is the canary in the cage". He observed that the rise and fall of the industry precedes and reflects the rise and fall of the economy as a whole. The games industry is extremely diverse, complicated and unpredictable, and surely a goldmine for researchers.

This is certainly not the first computer games-related journal. As some of our friends and colleagues asked us, why start another computer games journal? There are three main reasons:

\section{1: a lot of useful information goes missing}

Student dissertations and essays, and ideas and articles by industry professionals, seldom see the light of day in research journals. Countless student essays and dissertations are hidden in the back of lecturers' offices or tucked away in libraries, and are never read again. Furthermore, there have been some games research conferences with no proceedings, and the presentations by the speakers end up being archived and will eventually get deleted.

The Computer Games Journal will contain more than the standard academic papers. We also want to publish material sourced from student coursework and dissertations, proceedings of games conferences, and commentary (even blogs) from industry professionals.

\section{2: existing research tends to be limited in scope}

There is an abundance of academic papers on how computer games can be detrimental for individuals and society; or on some small algorithm (e.g. for making a sprite look more realistic); or on the applications for "serious" games.

We are not condemning researchers for working in these subject fields. However, it would be refreshing to find published research on other pressing and commercially relevant issues. For example, which games consoles are in decline, and why? What are the latest products, and what are the underlying technologies and business strategies? Which games consoles or platforms are on the ascendant, and why? What are the jobs on offer in the games industry? Where are these jobs, and how have these jobs changed in recent years? What technical and soft skills are required of games industry workers, and why is there a deficiency in the skills base? How do governments regulate the content on computer games and on their distribution? What are the impacts of current legislation, e.g. tax breaks or charges, or laws restricting or banning certain content? 


\section{3: we want this journal to reach the people - not the other way round}

Many academic journals appear stuffy and hark from a previous era. There are hundreds of journals, with the standard layout, which has existed for decades: all black and white, with the two columns of microscopic Times font. So many journals contain dozens of early/pre-1990s back issues, which do not exist online. Some games journals do exist entirely in an online format, but we want to do more than simply upload a paper onto the web:

- The Computer Games Journal will exist entirely online, and visitors will be allowed to download and print our papers.

- We will do away with the usual Times font and tedious layout: we will keep the layout simple, and include headings, tables and figures in colour in our publications.

- We will install a Disqus system, which will enable our readers to make comments beneath individual papers. We want this journal to feel more like a conference or a popular magazine, where public opinion and scrutiny is permitted.

Finally, we do not want The Computer Games Journal to become embedded within a national (i.e. British) mindset: submissions from students, academics and industry leaders from abroad will be warmly encouraged.

We appreciate that we are taking a high risk - and how appropriate, given that the computer games industry is a high- risk sector. Indeed, it is the element of Risk, which defines a game. Publishing a few dozen dreary-looking academic papers by a small elite with the right credentials is not taking much of a risk. Inviting researchers, students and industry professionals to disseminate and discuss information online; and improving the presentation and expanding the content of a journal, is more adventurous....and will surely be more memorable and worthwhile,

Dr John Sutherland (editor-in-chief);

Dr Tony Maude and Dr Malcolm Sutherland (deputy editors-in-chief). 